Radial and Nonradial Pulsations as Probes of Stellar Physics

ASP Conference Series, Vol. 259, 2002

C. Aerts, T.R. Bedding, \& J. Christensen-Dalsgaard, eds.

\title{
An Overview of Paul Smeyers' Career
}

\author{
A. Noels \\ Institut d'Astrophysique et Géophysique, Université de Liège, Belgium
}

I would just like to add a few words to what Paul Smeyers just said about Paul Ledoux. I worked with Paul Ledoux for a long time and I know that in addition to his own research and to the huge amount of courses he managed to teach, he supervised quite a number of $\mathrm{PhD}$ theses and I would like to spend some more minutes reminding you about another of his $\mathrm{PhD}$ students, one of the best-known of them, Paul Smeyers.

Paul Smeyers started his scientific studies at the Catholic University of Leuven, which was at that time still united with its French-speaking counterpart, now located in Louvain-la-Neuve. He graduated in mathematics in 1961 after an interruption from 1955 to 1959 to study theology at the High Seminar in Mechelen. In Leuven, he met Georges Lemaitre who, apart from being the great and now famous scientist we all know about, happened to be a French-speaking professor. As you know, Georges Lemaitre was a Canon and as such, he was obliged to celebrate a mass every morning. One of the task of young Paul Smeyers was to help him preparing the church for the mass. Georges Lemaitre was known to have a strong personality and Paul saw him refusing to say a single word in Dutch, not even dank u.

With a grant from the National Fund for Scientific Research, Paul Smeyers came to Liège at the Institut d'Astrophysique in 1961 as a PhD student to work with Paul Ledoux. It was just ten years after Paul Ledoux published in the Astrophysical Journal his pioneering work on: The non radial oscillations of gaseous stars and the problem of $\beta$ Canis Majoris. The subject chosen by Paul Smeyers will be a complete surprise to all of you since it is entitled: Non radial oscillations and stability of massive stars. The research was done quite rapidly and the thesis presented in 1966. It is in the form of two volumes with a total of about 320 pages written in French and typed, I guess, by the author himself.

At that time, nonradial oscillations were probably thought of by most astronomers as interesting games, challenging to their mind, but very seldom found in the real universe. Paul Smeyers was, and still is, someone not very easy to discourage and I quote from his introduction: Studying non radial oscillations is however far from devoid of interest. He stressed rapid rotation and magnetic fields as possible causes for non-spherical symmetry and therefore favourable to nonradial oscillations. He also set the stage for future research, already pointing out what has been present somewhere in his mind since then and up to now, which is: What happens to a pulsating star which is a member of a binary system?

In his thesis, however, stars were single and the main idea was to study non radial oscillations taking into account the perturbation of the gravitational potential. This had never been done before since, for non homogeneous models, the Cowling approximation was currently used. Huge amounts of computations 
had to be done, first with a Gamma ET Bull, which was a little more powerful than using your own fingers but much more complicated, and then with an IBM 7040, which was the Rolls Royce of that time but still very time consuming. Both computers had to be operated nearly manually or at the very least encouraged by the cheering presence of the scientist urging them to please hurry up and find something. At that time, $\mathrm{PhD}$ students were not allowed to enter the computing center at night, which was of course the best time to run the lengthy codes. To overcome this inconvenience, Paul Smeyers used to let himself be locked inside the computer room to have a brand new model in the early morning. That's how a theoretician gets the idea of an astronomer's observing night!

Another important part of this work was linked to the choice of massive stars. As you know, $g^{-}$-modes are related to convective instability but this aspect had only been discussed in models either completely convective or completely radiative. Paul Smeyers decided to investigate what happens in models where convection is only partly present. For that purpose, he chose massive stars with huge convective cores but radiative envelopes and he forced the temperature gradient to become superadiabatic in the core in order to trigger the appearance of a dynamical instability. He showed that $g^{-}$-modes are always present, whatever the extent of the convective region and whatever the superadiabatic excess of the temperature gradient. He called them convective modes. A very enlightening discussion of the nature of these modes can be found in Paul Smeyers' thesis, either in the text itself or in the form diagrams showing schematically the circular displacements for selected $g^{-}$-mode of $\ell=2$ in a massive star. These results were published, of course, in the Annales d'Astrophysique, one of the progenitors of $A \& A$.

While working so hard on his PhD thesis, Paul Smeyers could nevertheless find some time to join some members of the institute in somewhat different activities. Once a week, there was a volleyball or a basketball game in which Paul was an extremely active participant. I even heard some bad mouth saying that sometimes he could cheat a little bit to help his team. But that's nonsense of course!

After his $\mathrm{PhD}$, Paul Smeyers was called back to the Catholic University of Leuven, where he quickly became full professor in 1973 and where he had to teach astronomy, geodesy, mathematical and spherical astronomy, astrophysics and mechanics to students in mathematics and physics. A university professor has tasks at three levels, i.e., lecturing, research and administration. In general, one is expected to perform well in two of these, but throughout his career Paul Smeyers has continuously excelled in all three of them. He has been a very dedicated and conscientious lecturer, and the clarity of his courses and lecture notes, where he started from first principles and considered the content always in a broad physical context, has been very much appreciated by generations of students. He has throughout his career continued to cherish new mathematical developments in pulsation theory, and returned to them more vigorously than ever now that he has become free from other duties. During all these many years, the tremendous amount of time he spent to guide his students working on undergraduate or $\mathrm{PhD}$ theses has never decreased. During many years again, he has made his institute benefit from his administrative skills and vision and made it flourish and expand. If we are here today for this pulsation conference, 
to the series of which he has been contributing since the 70s when they started, it is largely thanks to him.

His research and his growing reputation earned him invitations in foreign institutes. Let me just point out some of them: a stay in South Africa, at the Boyden Observatory, a month spent at the Specola Vaticana at Castel Gandolfo near Roma, a visiting fellowship at JILA in Boulder, Colorado. In 1981, he was asked to become a visiting professor at the University of Arizona. He was also frequently invited to be a member of scientific organizing committees of international colloquia. This is always really a true recognition of his scientific merits and qualities.

He became member of the IAU in 1967 and later on, member of commissions 35 (Stellar constitution) and 27 (Variable stars). He was then member of the Space Science Committee of the European Science Foundation (from 1976 to 1986) and member of the Board of Directors of A\&A (since 1982). In Belgium, the list of honours is impressive. He was elected president of the Belgian National Committee for Astronomy (from 1981 to 1984), president of the Contact Group in Astronomy and Astrophysics from the National Fund for Scientific Research (since 1987), president of Third Cycle Studies in Astrophysics organized by the National Fund for Scientific Research (since 1981), member of the Belgian National ESO Committee (since 1982), member of the Royal Academy of Sciences, Letters and Fine Arts of Belgium and this list is not exhaustive.

If you ask the Astrophysics Data System to produce the list of Paul Smeyers' publications from 1966 up to now, you come out with 57 papers which is about 1.6 paper per year. I would like to comment on that because I have heard Paul stressing this point many, many times. It can be summarized in this way: It is not easy to produce a theoretical paper. He was always very angry with the ongoing system summing up the research work of a scientist through the number of publications per year. In the kind of subjects he was and still is tackling, one has first to put the problem into equations (each of them covering more than one page), second to solve them either analytically (very seldom), asymptotically (more often) or numerically (with no existing code to borrow) and third to discuss the solutions. Only after that you can think of writing a paper. I must add that Paul Smeyers' papers are generally about 20 pages long, with hundreds of equations. This was always a big problem for him: How can I reduce the length of a paper without losing the key-points of the problem ? Even a hard working very clever man like him cannot conceive and write such a paper in a month. I know he really suffered to see evaluations taking such a rough aspect and (don't repeat it) he more than once refused to complete a curriculum vitae and just threw the forms in the paper basket.

Notwithstanding the number of publications itself, it is a prodigious amount of work which stands in Paul Smeyers's papers. The subjects are often treated in a pioneering way and to me, it seems that nothing was difficult enough to rebuff him. The key-words are nonradial oscillations (of course), rotation, magnetic fields, tidal perturbations, asymptotic approximations etc., etc. One word you won't find, or maybe only in his early papers, is adiabatic as in adiabatic approximation since he decided one day, and vehemently argued about it, that isentropic should be used instead. This decision was made, according to my lecture of his papers, around 1985. 
In 1987 , there is a paper written in collaboration with a young astronomer, Christoffel Waelkens. Subject: Variable Be stars in h \& $\chi$ Persei. Other papers on SPB stars, on the main sequence broadening in the double cluster $\mathrm{h} \& \chi$ Persei and more recently on the famous 51 Pegasi star will show their two names associated. Apart from his close group, he also wrote papers in collaboration with Alfred Weigert, Morris Aizeman, Monique Tassoul and many others.

Paul Smeyers was the promotor of many PhD theses and I had the great pleasure and honour to be a member of many of the jurys. To be perfectly honest, the pleasure was not always to navigate through the numerous equations, symbols, theorems and so on, but it sure enough was in the ceremony itself, followed by a delicious meal at the Faculty Club of the KU-Leuven. The food was gorgeous and the company always cheerful. As I was afraid to take my car to come back to Liège with too little blood in my wine, I was always coming by train and Paul was kindly taking me back to the station. One evening, we missed the regular train. The next one was three hours later and everything was closed in or near the station. With an exemplary devotion to duty, Paul decided to wait with me on a bench alongside the platform in a terribly cold and black night. We talked about nearly everything, including of course nonradial oscillations. I must add that, for the next PhD jury, Paul reserved for me a room in the Faculty Club to be sure not to repeat that experience.

He had always three or four PhD students under his supervision at the same time. This is just amazing when you think of the work behind! All of these works have led to publications in A\&A joining the names of Paul Smeyers to that of his $\mathrm{PhD}$ student. After their thesis, these young scientists were perfectly trained in astronomy, mathematics, physics and numerical analysis. Most of them have found research positions in Belgian or foreign institutes.

I think that Paul Smeyers is one the few people in the world with such an intimate knowledge of all the problems of theoretical stellar stability, and being now moreover an expert in $\mathrm{LATE}_{\mathrm{E}} \mathrm{X}$, I wonder if he is not reserving us a big surprise for the future. Congratulations Paul ! 


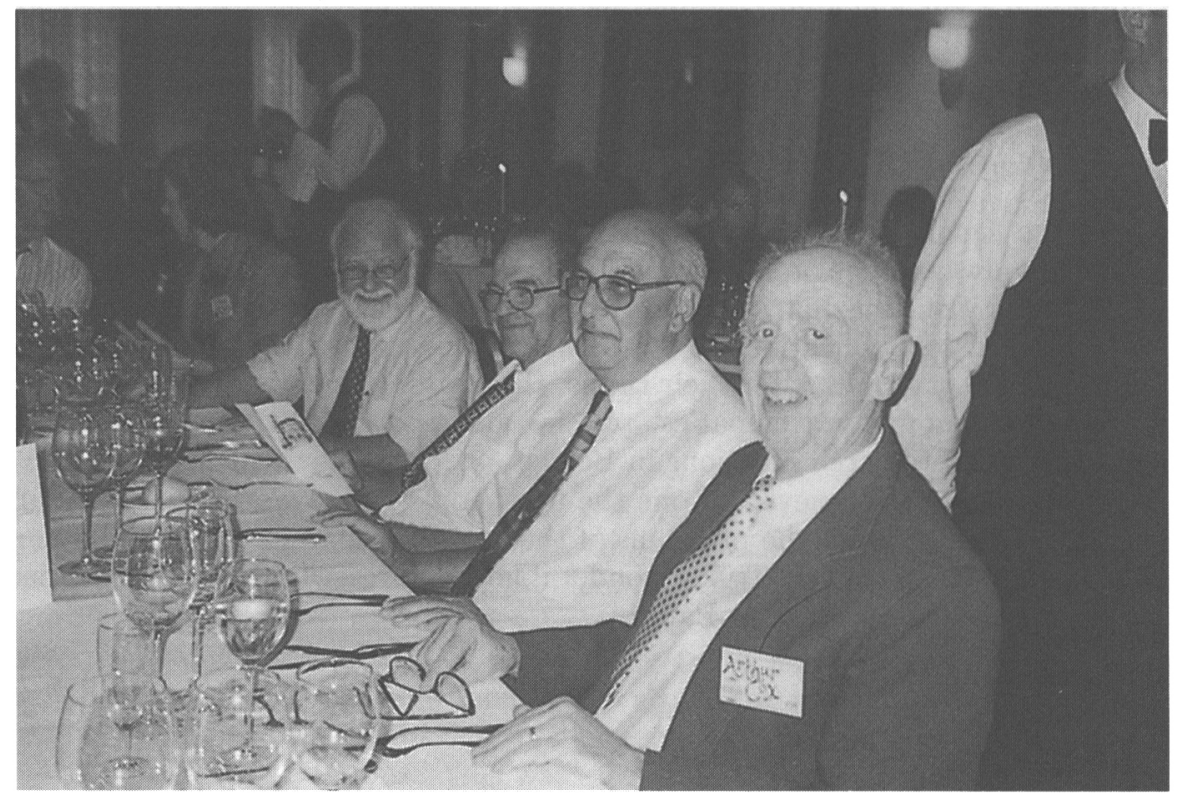

From right to left: Art Cox, Paul Smeyers, Wojtek Dziembowski and Douglas Gough, four eminent theoreticians enjoying each other's company during the conference dinner. 